\title{
Международно-правовая доктрина \\ и философия: аспекты взаимодействия
}

Шугуров М.В. *

Современные реалии глобализирующегося мира ставят перед международным правом новые задачи, связанные с расширением сферы его действия и увеличением масштабов международно-правового регулирования мировых процессов. Решение данных задач не может быть достигнуто без перехода международного права на новый уровень развития, что требует соответствующих изменений как в международноправовом мышлении, так и в международно-правовой доктрине.

Создание прочной теоретической базы не только в отечественной, но и в мировой науке международного права традиционно осуществляется при опоре на философские идеи и концепции. Как и любая наука, международно-правовая доктрина включает в себя философские основания. Наука права вообще и наука международного права в частности не может быть основана только на юридических понятиях. Историческое развитие международно-правовой доктрины в тесном взаимодействии с философией, прежде всего с политической и моральной, содействовало обеспечению науки международного права мировоззренческими и методологическими ориентирами, позволявшими как решать уже имевшиеся теоретические проблемы международного права, так и давать ответы на вновь возникающие вопросы. Более того, следует констатировать переплетение теории международного права не только с моральной и политической философией, но и с философией права ${ }^{1}$.

В современных условиях, когда международное право претерпевает серьезные изменения и когда обостряется вопрос о дальнейших перспективах его развития, происходит своего рода «философизация» международно-правовой науки. Тесное соприкосновение со смежными полями философских исследований заметно на уровне широко обсуж-

\footnotetext{
* Шугуров Марк Владимирович - д.филос.н., профессор Саратовской государственной академии права.

${ }^{1}$ Cм.: Leiter B. Naturalizing Jurisprudence. Essays on American Legal Realism and Legal Philosophy. Oxford, 2007; Exploring Law's Empire: The Jurisprudence of R. Dworcin. Ed. by S. Hershovits. Oxford, 2006.
} 
даемой темы международно-правовой ответственности ${ }^{2}$. Более того, между международно-правовой доктриной и философией происходят процессы взаимного сближения. Так, к проблематике дальнейших перспектив развития международного права в контексте формирования нового миропорядка обращается один из крупнейших философов современности - Ю. Хабермас ${ }^{3}$. Не обходят стороной философы, в частности философы морали, и более частные вопросы, например моральное ядро и моральную легитимность международного уголовного права ${ }^{4}$. Вместе с тем и сами специалисты в области международного уголовного права всесторонне рассматривают философские обоснования уголовного права и международного права ${ }^{5}$.

Современная теория международного права, стремясь всесторонне охватить международно-правовые явления, представлена целым рядом направлений: реализмом и такой его версией, как структурный реализм, институционализмом, социологией международного права, функционализмом, солидаризмом, институционализмом, феминизмом, менеджерализмом, либерализмом и т.д. Налицо диверсификация теории международного права, которая становится все более открытой по отношению к различным гуманитарным и социальным наукам. Следует отметить, что каждое направление в теории международного права включает в себя определенные философско-правовые основания. В частности, политико-ориентированная юриспруденция интегрирует в себя те или иные выводы политической философии. Либерализм как направление в современной англоамериканской теории международного права, как показывают исследователи современных направлений в американской международно-правовой юриспруденции, опирается на работы известного политического философа современности Ф. Фукуямы ${ }^{6}$. Следует также отметить, что имеет место и совпадение

${ }^{2}$ Proulx V.-J. Book Review: M. Ragazzi (ed.) International Responsibility Today: Essays in Memory of Oscar Schachter. Leiden; Boston, 2005 // European Journal of International Law. 2007. Vol. 18. № 3. P. 581.

${ }^{3}$ Хабермас Ю. Споры о прошлом и будущем международного права. Переход от национального к постнациональному контексту // Вопросы философии. 2004. № 3 . C. $12-18$.

${ }^{4}$ Altman A., Wellman Ch. Defense of International Criminal Law // Ethics. An International Journal of Social, Political and Legal Philosophy. 2004. Vol. 115. № 1. P. 35-67.

${ }^{5}$ См.: O' Shea A. Amnesty for Crime in International Law and Practice. Hague, London, 2002.

${ }^{6}$ CM.: Steinberg R., Zaslow J. Power and International Law // American Journal International Law. 2006. Vol. 100. № 1. P. 81; Democratic Accountability and Use of Force in International 
философских оснований тех или иных направлений в теории международного права с традициями в теории международных отношений. Так, традиция реализма восходит к Гоббсу и Макиавелли, традиция рационализма - к Гроцию, а революционизма - к трудам Канта.

Формирование в XX веке широких философских оснований международного права и его науки стало возможным благодаря отходу международно-правовой мысли от догм лидировавшего незначительное время позитивизма и возвращению в привычное русло признания многообразных источников международного права - культурных, моральных, социальных и, разумеется, философских. Так, например, один из основателей социологического подхода в международно-правовой теории М. Губер, помимо социальных оснований международного права, стал исследовать и другой метаправовой уровень - моральные основания международного права, которые в то время не воспринимались во всем объеме в рамках позитивистского подхода. В своем исследовании моральных аспектов международного права М. Губер продолжил традиции моральной философии Руссо и Песталоцци, а также целого ряда немецких философов морали ${ }^{7}$.

Активное обращение международно-правовой науки к философским основаниям базируется на методологическом положении о том, что развитие международного права опирается на то, что было достигнуто человеческой мыслью и практикой предшествующих эпох ${ }^{8}$. Важнейшим достижением человеческой культуры и цивилизации как раз и выступает философская мысль, которая оказывала и продолжает оказывать воздействие на научное познание. В такой отрасли современной философии, как философия науки, говорится о философских основаниях любого научного знания. Как и всякая наука, наука международного права имеет мощное философское основание. Это означает также и то, что в своем историческом развитии она была и продолжает оставаться вдохновленной философскими идеями, вырабатываемыми в рамках философии как особого мировоззренческого освоения мира. В признании высокой значимости философии для международного права нет преувеличения. Это определяется ценностью философии, яв-

Law. Ed. by C. Ku and H. Jacobson. Cambridge. 2002. P. 7.

7 Thürer D. Max Huber: A Portrait in Outline // European Journal of International Law. 2007. Vol. 18. № 1. Р. 78.

8 Фельдман Д.И., Баскин Ю.А. Учение Канта и Гегеля о международном праве и современность. Казань, 1977. С. 4. 
ляющейся динамично развивающимся миром идей и концепций. Обобщения, которые формируются в философии, распространяются на все науки и сферы человеческой жизнедеятельности. Не является здесь исключением и наука международного права. Значение философии для тех или иных сфер научных исследований может быть различным. Но сходно одно обстоятельство: без философии не могут сформироваться философско-правовые основания науки, в том числе международно-правовой.

В условиях дальнейшего развития и дифференциации науки международного права требуется выделение вопросов влияния философии на международное право и его науку в особую область международнотеоретических исследований. Вопросы подобного рода должны войти в предмет философии международного права. Те или иные философские взгляды, не переставая оставаться достоянием философии, стали составной частью теории международного права и заняли в системе ее общих вопросов прочное место. Однако при заинтересованном обращении к детальной проработке механизмов формирования и функционирования философско-правового блока в составе теории международного права можно увидеть, что существует целый ряд неразработанных и подчас еще не поставленных проблем. Именно философия международного права в качестве специального раздела международно-правовых исследований и в качестве особой международно-правовой дисциплины призвана тщательно изучать систему философско-правовых оснований и динамику их развития в контексте развития международного права и международно-правового мышления.

По всей видимости, вопрос о взаимоотношении философии и международно-правовой доктрины может ставиться и решаться в двояком ключе. Первый ракурс рассмотрения - это рассмотрение с точки зрения теории и истории международного права. Второй ракурс предполагает рассмотрение этого сюжета с точки зрения философии международного права. С методологической точки зрения данные ракурсы являются не изолированными, а взаимно переплетающимися. Философия международного права призвана включать наработки, сделанные в исследованиях по истории международного права и его науки. При этом она призвана осуществлять данный анализ с точки зрения своего предмета - выяснять причины и следствия «философской» настроенности представителей международно-правовой науки и ее как таковой в целом, с учетом плюрализма философского знания выявлять 
наиболее значимые философские течения в доктрине международного права, динамику их взаимодействия и смены.

В международно-правовой литературе накоплен богатый опыт исследования влияний взглядов отдельных философов и философских направлений на теорию международного права и ее школы. Наибольшее воздействие философия оказывала именно на теорию международного права. В теории международного права, как зарубежной, так и отечественной, имеются исследования, в которых при рассмотрении исторического развития международного права специальное место отводится взаимодействию философии и науки международного права. Без обращения к этому сюжету не обходится ни одна работа, посвященная вопросам развития международного права и его науки ${ }^{9}$. Сказанное означает, что философия не является духовным феноменом, который чисто случайно «врезается» в ткань международного права и его науки. Сама особенность философского мышления и его предметного поля делает вполне обоснованным то, что в ней затрагиваются вопросы войны и мира, сотрудничества между народами, создания справедливого миропорядка и т.д. Все это одновременно составляет и идейный комплекс международного права и его науки. Рассматривая науку международного права как науку о мире, В.Э. Грабарь видел ее задачу в упрочении мира на земле, в устранении войн из сферы международных отношений, подчеркивая, что это «сообщает науке международного права глубокий философский смысл» ${ }^{10}$.

Вопросы связи теории международного права и философии поднимались в свое время и в советской международно-правовой науке. В частности, при рассмотрении общетеоретических вопросов межгосударственных правоотношений В.А. Соколов, критикуя подход западной доктрины, отмечал, что идейные истоки западных учений о международно-правовой связи между государствами ведут свое начало от философских идеалистических концепций ${ }^{11}$. Рассматривая же общетеоретический вопрос о соотношении международного и внутригосударственного права, Д.Б. Левин указывал на то, что начало

\footnotetext{
${ }_{9}^{9}$ Василенко В.А. Основы теории международного права. Киев, 1988. С. 18-20, 122-123; Анцилотти Д. Курс международного права. М., 1961. Т. 1. С. 24-28; Фердросс А. Международное право. М., 1959. С. 35-38, 71.

10 Грабарь В.Э. Война и международное право // Ученые записки Императорского Юрьевского университета. 1893. № 4. С. 25.

11 Соколов В.А. Теоретические вопросы межгосударственных правоотношений. Красноярск, 1988. С. 188.
} 
монистической теории «примата» внутригосударственного права над международным берет свое начало у Гегеля ${ }^{12}$. Сохранение интереса к философско-правовым аспектам общетеоретических проблем характерно и для современной российской международно-правовой доктрины.

Отечественная наука международного права отличается не просто привлечением взглядов тех или иных философов для обоснования общетеоретических позиций и не эклектичным использованием выводов философов, а продуманной фундированностью науки международного права с точки зрения философской обоснованности. Выводы философии, касающиеся проблематики международного права, как в дооктябрский, так и в советский период органично встраивались в международно-правовую теорию, становясь ее достоянием. Имело место и глубокое обоснование связи философии и международного права. Не перестает оставаться актуальным и еще один аргумент в пользу тесной связи философии и международного права, высказанный Ю.А. Баскиным и Д.И. Фельдманом. По их мнению, «чем шире размах социального действия, тем глубже и важнее значение философского знания. Проблемы смысла существования человечества, основных эпох и тенденций его развития - это проблемы не только (и не столько) внутригосударственные, но и в не меньшей мере международные. Взаимная связь философии и международного права особенно четко выступает в наши дни. Быть или не быть человечеству - это ныне не вопрос абстракции и фантастических домыслов, а реальная проблема, положительное решение которой, безусловно, возможно, но требует при этом усилий всех прогрессивных и миролюбивых сил, усилий материальных и идеологических» ${ }^{13}$.

Выводы о тесной связи теории международного права и философии вполне релевантны и в отношении историко-правового подхода к международному праву. Обращение к истории международного права показывает, что одной из традиционных наук, с которой, уже начиная с эпохи античности, взаимодействовало международное право и международно-правовое сознание ${ }^{14}$ и с которой с самого начала своего

12 Левин Д.Б. Актуальные проблемы теории международного права. М., 1974. C. 192.

13 Фельдман Д.И., Баскин Ю.А. Указ. соч. С. 4.

${ }^{14}$ См.: Вязгин А.С. Международное право в Средние века (По поводу книги барона Таубе). СПб., 1900. 
возникновения (в XVI-XVII вв.) была тесно связана наука международного права, была философия. Философия и ее идеи, относящиеся к предмету международного права, играли важную роль не только в процессе становления, но и в процессе эволюции науки международного права. На всем протяжении средних веков и вплоть до конца XVI века данные идеи носили религиозный характер и в определенном смысле находились в тени богословия. После того как в начале XVII века международные отношения в условиях секуляризации получили рациональные основания, а сама наука международного права благодаря усилиям Г. Гроция получила дисциплинарное оформление как отрасль правоведения, идеи новоевропейской философии стали оказывать продуктивное воздействие на идейное содержание науки международного права и его методологию. Механизмы влияния и воздействия философских идей не только на теорию, но и на всю доктрину международного права не представляют собой специального интереса для самой философии, но их обсуждение является весьма важным и продуктивным для доктрины международного права.

Сказанное означает, что философия является одним из источников формирования международно-правового сознания и международного права в целом. Именно одним из источников, и, разумеется, не единственным. Так, исследуя международное право в эпоху античности, В. Бедерман обращается преимущественно к таким источникам (в широком значении слова) международного права, как дипломатические отношения, мораль, обычаи, религия. Помимо этого он прослеживает степень проявленности идеи международного общения 15 . Как бы то ни было, но именно философия придает данным источникам (в терминологии Д. Бедермана, «метафизическим») концептуальное оформление. Не будет искажением положения дел сказать и о том, что и наука международного права в качестве своего источника имела отдельные положения, которые высказывали не только представители юридического сословия, но и философы. Достаточно привести в качестве примера творчество И. Бентама, который, будучи по образованию юристом, а по призванию философом, подготовил план международного кодекса (1802 г.), а также преамбулу к нему (1827 г). Более того, как подчеркивал В.А. Василенко, именно Бентаму мировое сообщество обязано широким восприятием самого термина «международное право» и пониманием его как права, создаваемого в процессе

${ }^{15}$ Bederman D. International Law in Antiquity. Cambridge, New York. 2001. 
межгосударственного общения ${ }^{16}$. Однако при этом следует иметь в виду, что наука международного права возникла не из философии, а посредством философии. Данное замечание является объяснением того факта, что наука международного права и само международное право развиваются не только под непосредственным, но и под опосредованнылм влиянием философских идей, которые находят свое преломление как в теоретических (доктринальных), так и в нетеоретических (ментальных) формах международно-правового сознания. Указанное обстоятельство призвано еще раз подчеркнуть то, что взаимодействие философии и международного права должно оцениваться и исследоваться предельно взвешенно - без преувеличения и без преуменьшения воздействия философии на международное право и его науку.

В ряде случаев философия может дать толчок в форме идеи и включиться в философско-правовые основания международного права именно в таком качестве, позволяя лучше сформулировать мысли, которые витают в головах юристов-международников, которые на первоначальных этапах развития доктрины международного права, как Г. Гроций, сами были философами.

В ряде случаев бывает затруднительно провести границу между философскими и собственно доктринально-международными суждениями того или иного мыслителя. Например, Г. Гроций был одновременно, как известно, не только юристом-международником и основателем науки международного права, но и философом, который впитывал наиболее актуальные и перспективные для своего времени философско-правовые идеи. С этим соглашается и Анцилотти, который прямо отмечает, что Гроций заложил философско-юридические предпосылки международного права и его науки ${ }^{17}$; правда, этим двойственным основаниям сам Анцилотти не симпатизировал и поэтому ставил Джентиле выше Гроция, поскольку у первого явное преимущество отдавалось сугубо юридическому методу и духу.

Примечательно, что на доктрину международного права влияли не только взгляды того или иного философа, но и общие философские взгляды, например философия международного права, которая концептуализировалась во взглядах философов Нового времени. В дальнейшем на доктрину международного права оказывали воздействие не только персональные, но и имперсональные философские идеи

${ }^{16}$ Василенко В.А. Основы теории международного права. Киев, 1988. С. 18.

17 Анцилотти Д. Указ. соч. С. 24. 
и концепции, что обеспечило достаточно интересную конфигурацию философско-правовых оснований международного права и его науки. Так, например, на формирование позитивистского подхода в международно-правовой доктрине, связанного с отказом от теоретических обобщений и сведением правового регулирования к отдельным казусам, повлияли не только взгляды философов-позитивистов, но и сам дух контовского позитивизма ${ }^{18}$. Под воздействием духа позитивизма в юридической науке Дж. Остином были выработаны общие принципиальные представления о праве, которые стали составной частью философско-правового основания не только национального, но и международного права, оказавшего влияние на формирование одного из направлений в философии международного права - международно-правового позитивизма.

Не трудно догадаться, что наука международного права в своих отношениях с философией не могла избежать той логики, которая присуща взаимоотношению философии и науки вообще: от пиетета к отрицанию и обратно - к признанию значимости философии, но уже на новых, диалогических основаниях. Дух позитивизма в доктрине международного права, который отрицал значимость философии, как и особое место международно-правовой доктрины в развитии международного права, не был всеобщи и продержался сравнительно недолго. Справедливости ради надо сказать, что он затронул и отечественную науку международного права. В частности, известный дореволюционный юрист-международник М.Н. Капустин полагал, что наука международного права найдет более твердую основу в мемуарах и нотах государственных людей, чем в «школьных умозрениях». В начале XX века позитивизм критиковался естественно-правовым подходом в международном праве, который продолжал свое существование и который имманентно был сопряжен с философскими общениями. Во второй половине XX века произошла маргинализация позитивизма под воздействием возрожденной в небывалом масштабе традиции естественного права, а также под влиянием марксистской доктрины, которая, в свою очередь, следует отметить, негативно относилась и к первому, и ко второму подходу.

Наука международного права никогда не увлекалась отрицанием ценности философского знания. В подавляющем числе случаев она признавала значимость философских обобщений, без которых, как

18 Корецкий В.М. Избранные труды: В 2 кн. Киев, 1989. Кн. 2. С 184. 
отмечал еще в позапрошлом веке И.И. Ивановский, причина движения огромного механизма (имеется в виду историческое развитие международного права. - М.Ш.) будет от нас навсегда скрытой ${ }^{19}$. Хотелось бы напомнить, что и позитивизм в науке XIX века как таковой, даже самый радикальный, оставлял место для работы философского мышления внутри науки. Разумеется, наука международного права никогда не приходила к идее отрицания самостоятельного статуса существования философии; напротив, она всегда испытывала интерес и симпатию к тому или иному не всегда современному, но всегда идейно значимому кругу философских идей, высказывавшихся в том или ином направлении философии.

Задача повышения эффективности международного права и достижения его целей требует создания как можно более адекватной картины мировых процессов, к регулированию и воздействию на которые призвано международное право. Международно-правовая наука не только исследует международное право, его состояние и перспективы развития, но и сочетает обсуждение данных вопросов с исследованием условий, обстановки такого существования и развития, ибо пути развития международного права пролегают в среде мировых процессов. Поэтому далеко не случайно, что обязательным атрибутом международноправовой доктрины являются мировоззренческие обобщения.

Международное право не только призвано к обеспечению решения текущих проблем, но и нацелено на реализацию определенного идеала миропорядка. Как верно отметил В.И. Евинтов, «юристы-международники дают свою картину мира (осуществляют правовой анализ современного миропорядка. - М.Ш.), палитра которой варьируется от трезвых оценок и позитивно рассматриваемых перспектив развития (международного. - М.Ш.) сообщества до пессимистических констатаций невозможности существования последнего» ${ }^{20}$. На наличие мировоззренческих обобщений указывает и С.В. Черниченко, который отмечает, что «как только начинают затрагиваться вопросы, связанные с происхождением государства и права, оценкой их демократичности и т.д., неизбежно обращение к философии, к мировоззренческим аспекта исследования, и тогда придерживаться формально-логическо-

\footnotetext{
${ }^{19}$ Цит. по: Корецкий В.М. Указ. соч. Киев, 1989. Кн. 2. С. 233-234.

${ }^{20}$ Евинтов В.И. Международное сообщество и правопорядок (анализ современных концепций). Киев, 1990. С. 5.
} 
го метода без учета идеологических постулатов нельзя» ${ }^{21}$. В процессе создания картины мира юристы-международники явно или неявно опираются на различные философские обобщения мировых процессов, прежде всего на политическую и моральную философию. Современная философия далека от обсуждения вопросов о мировой ситуации исключительно на языке, понятном только специалистам. Данные рассуждения ориентированы на широкую аудиторию, что одновременно приводит к проблеме ответственности самой философии за формирование международно-правового сознания.

Философские выводы и взгляды не могут быть проигнорированы международным правом и его наукой в связи с тем особым положением, которое занимает философия в западной культуре и цивилизации. Данное место пока что не может занять ни одна из других областей человеческой духовности. В западной традиции в рамках присущего социокультурного кода философия воспринимается как высший тип истины: «где философия, там и истина». Как отмечал величайший философ XX века М. Хайдеггер в своей работе «Письмо о гуманизме», философия обладает всемирно-историческим престижем и рассматривается как нечто, находящееся по ту сторону повседневности, доступное только посвященным. Если интерпретировать данную мысль в более рациональном ключе, то следует заключить о том, что к философии обращаются с целью обоснования политико-правовых построений. Более того, подобные обобщения вырабатывались и самой философией на своей собственной основе. В присущем философии богатстве идей и многообразии концепций есть такие, которые воспринимаются и плодотворно развиваются в науке международного права, что позволяет достигнуть обогащения последней.

Траектория развития науки международного права в определенной степени зависит от процессов, происходящих в дисциплинарно организованном философском мышлении, по причине их категориальной близости. Так, если бы не было кантианства, гегельянства, марксизма, прагматизма и иных плодов историко-философского процесса, то трудно было бы представить современную науку международного права, находящуюся на столь значительных концептуальных высотах. Однако несомненным и бесспорным является тот факт, что сама философская и международно-правовая мысль определяется не только духом

21 Черниченко С.В. Теория международного права: В 2 т. М., 1999. Т. 1. Современные теоретические проблемы. С. 8-9. 
эпохи, но и объективным балансом интересов государств и иных субъектов международного права на международной арене. Однако опять же данные интересы, получая свое отражение и развитие в различных политико-правовых доктринах, не могут миновать ни дисциплинарно организованной философии, ни тех философских идей, которыми преисполнено международно-правовое сознание.

Важным методологическим ориентиром исследования взаимодействия международного права и философии может послужить подход, в соответствии с которым такую связь не следует недооценивать, но нельзя и переоценивать. Международное право и его наука не являются механическим преломлением философии международного права в указанных двух ее пониманиях, но, с другой стороны, моменты такого немеханического преломления, разумеется, существуют, и их нельзя недооценивать. Процесс преломления не носит вынужденного или насильственного характера: философия по самой своей природе не склонна к навязыванию выработанных ею идей. Философия определяет ориентиры развития международного права и его философии, но не делает этого за международное право и его науку. К тому же если исходить из плюрализма философских учений, то философское воздействие на международное право и его науку предстает как многонаправленный процесс, оставляющий и моменты неопределенности. Дело объясняется логикой международно-правового мышления, нуждающегося в идеях наибольшей степени общности, которые далее конкретизируются в категориях и терминах юридического научного мышления. Так, говоря о международном праве как важнейшем идеологическом явлении современного общества и подчеркивая неотделимость внешнеполитической деятельности государства от науки международного права, Д.И. Фельдман и Ю.А. Баскин подчеркивали, что «характерной чертой международного права является его тесная связь с философским знанием. Наличие этой связи вполне понятно, так как в международном праве и его теории получают свое выражение коренные вопросы существования человечества в целом» 22 . Вполне очевидно, что международное право потому и востребовано международным общением, что способно регулировать мировые процессы именно в контексте решения коренных вопросов человечест-

22 Фельдман Д.И., Баскин Ю.А. Учение Канта и Гегеля о международном праве и современность. Казань, 1977. С. 4. 
ва. Это качественная сторона международного права, которая находит свое отражение в его философии.

Причиной влияния философии на все стороны общественной жизни является ее связь с истиной. Однако следует отметить, что философия не есть репрезентация вечной и неизменной истины, а есть стремление к истине. В противном случае, если бы философия была единственным глашатаем истины, то не существовало бы ни религии, ни искусства, ни науки. Следует отдавать отчет и в том, что стремление к истине порождает разные артикуляции истины. И хотя М. Хайдеггер говорил о том, что великие мыслители говорят одно и то же, но по-разному, все же следует уточнить, что они не только говорят по-разному, но и говорят о разном, что не мешает им находиться в общем поле искания истины. В этом же русле шли размышления и Г. Гроция, который придерживался, как сам об этом пишет, взглядов древних христиан о том, что «нет такой философской школы, которой была бы доступна вся истина, хотя и нет такой, которая не содержала бы частичной истины» ${ }^{23}$. Признание плюрализма философских истин может быть ценным для международного права только в том случае, если данный плюрализм касается сторон одной истины. Релятивистский же плюрализм, предполагающий сосуществование несоприкасающихся истин в духе постмодернистских веяний вряд ли продуктивен для философии общего международного права. На международное право влияние оказывает не только философия как форма общественного сознания, но и различные философские традиции. Скажем прямо, международное право и его наука во всемирном масштабе отражает дискуссионное поле разных направлений в философии.

В правоведении, в том числе и в науке международного права, имеется определенный пиетет по отношению к философии, что подчас приводит к абсолютизации того или иного философского направления или взглядов того или иного мыслителя. Например, в послевоенные годы в рамках ренессанса католической версии естественно-правовых теорий стали превозноситься идеи Ф. Аквинского. В рамках же советской доктрины международного права абсолютизировались выводы марксистско-ленинской философии, которые сейчас утратили свою актуальность в качестве единственно верного обоснования науки международного права. Вместе с тем это не означает, что марксизм может быть просто-напросто отброшен. Как известно, один из видных

${ }^{23}$ Гроций Г. О праве войны и мира. М., 1956. С. XLII (Посвящение). 
мыслителей современности Валлерстайн основывает свой мироанализ на определенных марксистских идеях. В этой связи вполне обоснованными выглядят идеи С.В. Черниченко о том, что многие выводы классиков марксизма при исследовании в определенном, «земном ракурсе» общественных явлений представляются справедливыми и в настоящее время ${ }^{24}$. Среди многочисленных современных моделей, подчас оригинальных и порой экстравагантных, появляющихся в ходе дальнейшей эволюции международного права и его роли в современной системе международных отношений, достаточно респектабельным является видение международного права как определяющей силы в международных делах, способствующей поддержанию справедливого международного порядка 25 .

В том случае, когда мы говорим о философии международного права не как о разделе науки, а как о философских основаниях международного права и его науки, следует сразу же оговориться, что это сложная композиция идейно выраженных позиций. Творческая природа международно-правового мышления приводит к тому, что те или иные идейные положения не воспринимаются из философии или же из идейного багажа в неизменном виде в качестве единственно верного ориентира. В самой международно-правовой доктрине имеются случаи сопротивления такой механической рецепции, которая способна привести к ошибочным международно-правовым последствиям. В частности, в советской доктрине вызвало несогласие распространение правовой концепции общего наследия человечества на охрану окружающей среды и климатические проблемы, на культурные и художественные ценности. Признавалось, что в философском смысле достижения науки, искусства и литературы являются общим достоянием человечества, «но это существенно отличается от правовой концепции ОНЧ, заложенной в Конвенции ООН по морскому праву 1982 г.» ${ }^{26}$. Противопоставляет позиции юриста-международника и философа и Д. Анцилотти, который берет под сомнение философию как таковую по причине своих позитивно-правовых позиций. Так, он указывает, что международное право универсально только в философском

24 Черниченко С.В. Теория международного права: В 2 т. М., 1999. Т. 1. Современные теоретические проблемы. С. 7.

${ }^{25}$ Mievile Ch. Between Equal Rights: A Marxist Theory of International Law. Leiden; Boston, 2005.

${ }^{26}$ Клименко Б.М. Общее наследие человечества. М., 1982. С. 35-36. 
плане - плане пожеланий, но не в юридическом. И если философ может строить понятие универсальной Лиги Наций, то юрист принимает ее такой, какой она есть, исходя из определяющих ее норм и признавая отсутствие ее универсального характера «даже если бы и возможно было ориентировать ее в сторону идеальной и, конечно, желательной универсальности» ${ }^{27}$.

Еще раз подчеркнем, что философия не является глашатаем абсолютной истины: философии также могут ошибаться. В качестве примера можно привести взгляды Ф. Фукуямы, который в последнее время скорректировал свои взгляды о перспективе близкого конца истории как победы либеральных ценностей во всем мире. С существованием ошибок у Гегеля соглашался и А. Фердросс, отмечая, что Гегель проглядел неизбежное несоответствие между идеей права и позитивным правом. Следует указать и на тенденцию корректировки некоторых философско-правовых выводов, сделанных собственно философами, со стороны международно-правовой науки. Так, корректировка философского понимания фикций в праве, в том числе в международном, предложенная философом Х. Вайхангером, была осуществлена Кельзеном ${ }^{28}$. Определенное несогласие с позицией того или иного философа может выразиться в опоре на другого философа, который развивает иные взгляды или является в данный период «модным». В частности, события конца XX века не подтвердили выводов Ф. Фукуямы о «конце истории». Определенные тенденции мирового развития оказались созвучны выводам С. Хантингтона о столкновении цивилизаций. Достаточно интересным является факт ссылки на статью С. Хантингтона, опубликованную в 1993 г. в ходе дискуссии относительно ст. 9 Статута Международного суда $\mathrm{OOH}^{29}$.

Сложность философско-правовых оснований международно-правовой доктрины определяется сочетанием различных философских концепций. При этом философские основания включают в себя не просто идеи Канта, Маркса, Гегеля, а идеи в их интерпретации со стороны того или иного представителя международно-правовой науки или соответствующего направления. Отсюда философия присутствует

27 Анцилотти Д. Указ. соч. С. 97.

${ }^{28}$ См.: Vermeer-Kǘnzli A. As If The Legal Fiction in Diplomatic Protection // EJIL. 2007. Vol. 18. № 1. P. 45.

${ }^{29}$ The Statute of the International Court of Justice A Commentary. Ed. By A. Zimmermann, Ch. Tomuschat, and K. Oeller-Frahm. Oxford, New York, 2006. P. 170. 
в международном праве и его науке в превращенном виде, т.е. не прямо, а опосредованно - через интерпретации философских идей относительно международных отношений и международной жизни со стороны самих же юристов-международников.

Однако нельзя умалять и прямого воздействия философских идей. Прямое воздействие оказывали великие философы, которые в своих философских исследованиях практически сумели выйти на уровень доктринального международно-правового мышления и мыслили уже не просто как философы, а отчасти как юристы-международники. Мы имеем в виду Канта и Гегеля, которые ввиду различия их философий различным образом оказали влияние на международное право. Выбор того или иного философа и сформулированных им идей определяется многими факторами. К одному из таких факторов можно отнести «философское самоопределение» того или иного юриста-международника и той или иной школы в целом. Как показывает M. Koskenniemi в третьем очерке с весьма характерным названием «Международное право как философия: Германия, 1871-1933», входящем в его книгу, наука международного права этого периода в Германии пыталась согласовать сферу государственности и сферу международного правопорядка, используя при этом философские теории свободы и автономии в целях согласования данных сфер. Вовсе не удивительно, что над всеми трудами этого периода «нависло» плотное присутствие Канта и Гегеля ${ }^{30}$. Примечательно, что, в частности, в философии международного права Кельзена как основоположника «идеалистического» направления в юридическом позитивизме, нашли свое совмещение мировоззренческие и методологические ориентации неокантианского трансцендентализма и гегелевского понимания международного права. Подобный симбиоз стал и философским основанием монистической теории Кельзена.

К другим факторам обращения к философии следует отнести и правила хорошего тона, принятого в международно-правовой науке. Так, например, свой курс международного права известный итальянский юрист-международник А. Кассес открывает со ссылки на методологическое замечание Б. Рассела относительно преимуществ и недостатков присутствия деталей в научных книгах ${ }^{31}$. К числу других факторов сле-

${ }^{30}$ Koskenniemi M. The Gentle Civilizer of Nations: The Rise and Fall of International Law, 1870-1960. Cambridge, New York, 2001. P. 181-182.

${ }^{31}$ Cassese A. International Law. Oxford, 2001. P. V. 
дует отнести отыскание новых идейных стимулов. Идейные стимулы также возникают либо из открытия новых имен, либо из обращения к новому прочтению тех или иных философско-правовых взглядов, которые вполне относятся к классике. Философско-правовые концепции обладают способностью к обратному свертыванию - т.е. обратному движению к идее, а от идеи - опять к концепциям, но уже новым. Эти идеи являются тем фундаментом, на котором научная международноправовая мысль творит свои концепции. Более того, эти идеи начинают одновременно выполнять роль ценностей и идей, которые способны повлиять на наполнение международно-правового сознания и его теоретико-доктринальной формы передовыми идеями и ценностями. Так, в самом начале XX века Л.А. Комаровский, анализируя круг изданий по проблеме международного мира и способов его достижения, отмечал, что работа Канта «О вечном мире» не утратила значения в наши дни ${ }^{32}$. Актуальность представлений И. Канта о «вечном мире» и мировом порядке подтверждается и в философии XX-XXI веков ${ }^{33}$.

В заключение следует констатировать то обстоятельство, что логика взаимодействия философии и доктрины международного права была и остается направленной на достижение конкретных целей. Они заключаются в создании методологической и мировоззренческой базы для решения теоретических и практических проблем международного права. По этой причине проблема перманентной модернизации философско-правовых оснований международно-правовой науки отличается непреходящей актуальностью.

32 Комаровский Л.А. Гаагская мирная конференция. М., 1902. С. 11.

${ }^{33}$ См.: Актуальность Канта. СПб., 2005; Иммануил Кант и актуальные проблемы современной философии: Сборник научных трудов. М., 2008. Т. 2. С. 36-40, 45-51. 


\section{International Legal Doctrine and Philosophy: \\ Aspects of Interaction}

(Summary)

\section{Mark V. Shugurov*}

Article is devoted to analysis of relation between international legal theory and philosophy. Author asserts that moral, political and legal philosophy is having a great significance in international legal doctrine. Interaction philosophy and international legal doctrine in modern period of development international law realize in the contest of increasing interdisciplinary issues. The formation of thoughtful philosophical underpinnigs of international law and his theory have determined of the falling of the positivists dogma. In this article the author argue that international legal theory possess of inherent philosophical foundations. They have been divided into methodological and ideological foundations. Philosophy influences on their development. Author of the article review the philosophical basis of the international legal theory as an object of the philosophy of international law. Separate attention put up analysis of direct and indirect philosophical impact on international legal doctrine. Reason for great significance philosophical ideas is central role of philosophy as a spirits phenomenon of culture. In modern epoch philosophical pluralism is expanding. Diversification of the philosophical conceptions complicates the philosophical basis of international law doctrine. Philosophical basis include idea of oldest philosophers and conception of modern philosophers. Also they include the philosophical views of international lawyers. Author of article suggests to modernize philosophical basis of international law and his doctrine and to establish the mutual consent in the sphere of the philosophical foundations of the international law.

* Mark V. Shugurov - Doctor of Laws, professor of the Saratov State Law Academy. 